\title{
Attitudes about Medical Malpractice: An American Society of Neuroradiology Survey
}

\author{
N.P. Pereira, J.S. Lewin, K.P. Yousem, and D.M. Yousem
}

\begin{abstract}
SUMMARY: The concern over medicolegal liability is pervasive among physicians. We sought, through an email survey to the members of the ASNR, to assess the experience with and attitudes about the medicolegal environment among neuroradiologists. Of 4357 physicians surveyed, 904 answered at least 1 of the questions in the survey; 449 of 904 (49.7\%) had been sued: 180 (44.9\%) had been sued once, 114 (28.4\%) twice, 60 (15.0\%) 3 times, and 47 (11.7\%) more than 3 times. The payouts for suits were most commonly in the $\$ 50,000$ to $\$ 150,000$ range, except for interventional neuroradiologists, in whom the most common value was $\$ 600,000$ to $\$ 1,200,000$. Only 9 of 481 (1.9\%) of suits returned a plaintiff verdict. Despite reported outcomes that favored physicians with respect to cases being dropped $(270 / 481=$ $56.1 \%)$, settled without a payment $(11 / 481=2.3 \%)$, or a defense verdict $(46 / 481=9.6)$, most respondents $(81.1 \%, 647 / 798)$ believed that the medicolegal system was weighted toward plaintiffs. More than half of the neuroradiologists $(55.2 \%, 435 / 787)$ reported being mildly to moderately concerned, and 19.1\% (150/787) were very or extremely concerned about being sued.
\end{abstract}

ABBREVIATIONS: $A$ ANR $=$ American Society of Neuroradiology; PIAA = Physician Insurers Association of America

M alpractice lawsuits are a significant source of concern for physicians. ${ }^{1}$ In one report of physicians covered by a large professional liability insurer, $7.4 \%$ of physicians had a claim made against them every year. ${ }^{2}$ There is a high variation of probability for facing a claim within medical specialties. Obstetricians/gynecologists, internists, family physicians, general surgeons, and orthopedists are more likely to be sued than radiologists. ${ }^{3}$ Of the top 10 specialties sued, plastic surgeons, anesthesiologists, cardiologists, and gastroenterologists are named less frequently than are radiologists as defendants in malpractice suits. ${ }^{4,5}$ Radiology also occupies the 6th position in terms of dollars paid per claim. ${ }^{5}$ Overall, approximately $30 \%$ of radiologists will be the subjects of at least 1 malpractice claim during their careers. ${ }^{6}$ The highest rates of claims of malpractice suits that include radiologists classified by organ system category are breast, followed by vertebral/musculoskeletal, pulmonary, and gastrointestinal systems. ${ }^{6}$ CNS-related claims ranked sixth among organ systems. ${ }^{4}$

Once a claim is made, the mean time between an injury claim being served and its resolution is 5 years, which means that the

Received July 22, 2013; accepted July 24.

From The Russell H. Morgan Department of Radiology and Radiological Science, The Johns Hopkins Medical Institution, Baltimore, Maryland.

Please address correspondence to David M. Yousem, MD, MBA, Johns Hopkins Medical Institution, $600 \mathrm{~N}$ Wolfe St, Phipps B100F, Baltimore, MD 21287; e-mail: dyousem1@jhu.edu

三 Indicates article with supplemental on-line table

http://dx.doi.org/10.3174/ajnr.A3730 time taken to resolve the case can seem interminable to the parties involved. ${ }^{7}$ However, accordingly to the Physician Insurers Association of America (PIAA), 65\% of claims are dropped, dismissed, or withdrawn; $25.7 \%$ are settled; and 5\% are resolved by trial. ${ }^{4}$ Sixty percent of all radiologists' claims that are resolved out of court result in a payment to a plaintiff. On the contrary, when a case goes to trial, $80 \%$ of verdicts are in favor of physicians. ${ }^{7}$ The mean legal costs associated with cases that go to trial, are settled, or are dropped/dismissed/withdrawn are $\$ 375,000, \$ 200,000$, and $\$ 40,000$, respectively. $^{3}$

Although there have been many studies published on medical malpractice in the United States, the experience and attitudes of neuroradiologists specifically have not been addressed. This study was designed to evaluate the opinions of neuroradiologists toward malpractice suits and the judicial system. On the basis of the experience in our own institution, in which less than $20 \%$ of the faculty have been named in a suit, we hypothesized that a minority of American Society of Neuroradiology (ASNR) members would have been named in malpractice suits. On the basis of the level of anxiety experienced within our own division, despite the low rate of suits, we hypothesized that the fear of being sued would outweigh the actual experience of ASNR members.

\section{MATERIALS AND METHODS}

Our data were based on an e-mail survey of 4357 ASNR members conducted in February 2013. The survey questions from which this report is based can be found in On-line Table 1. 


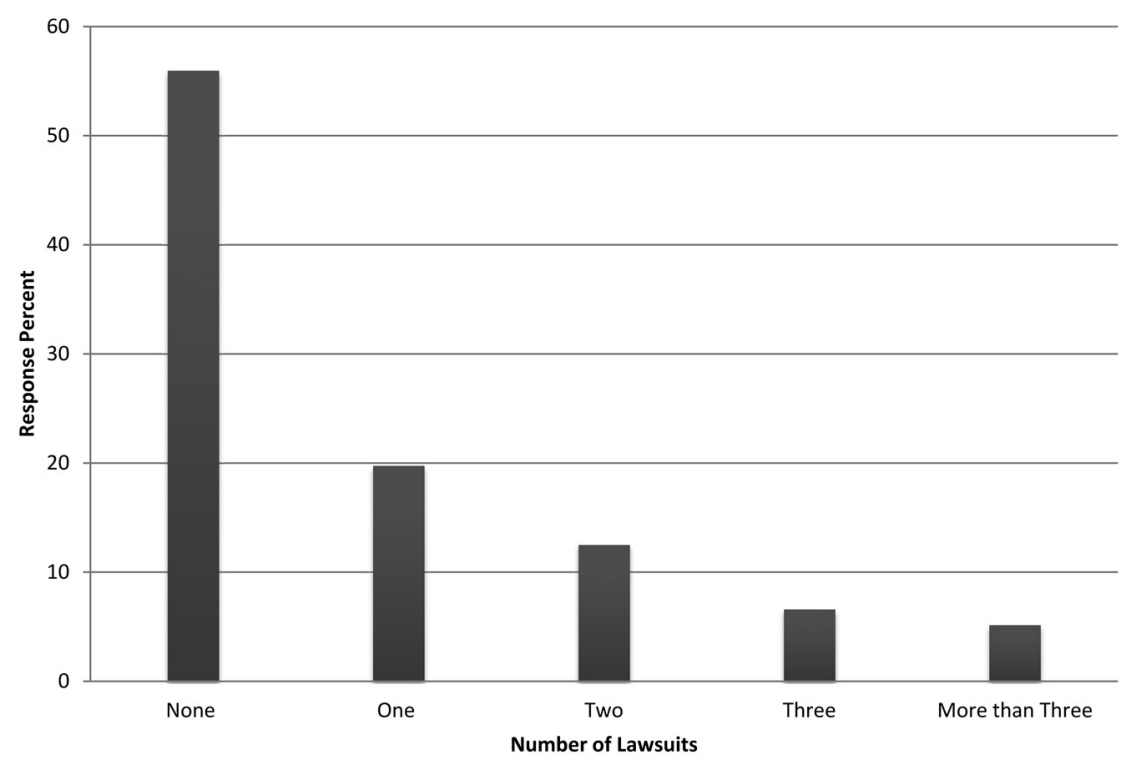

FIG 1. Distribution, in percentage, of lawsuits a radiologist has been named in (total of 776 lawsuits from 401 respondents who had been sued).

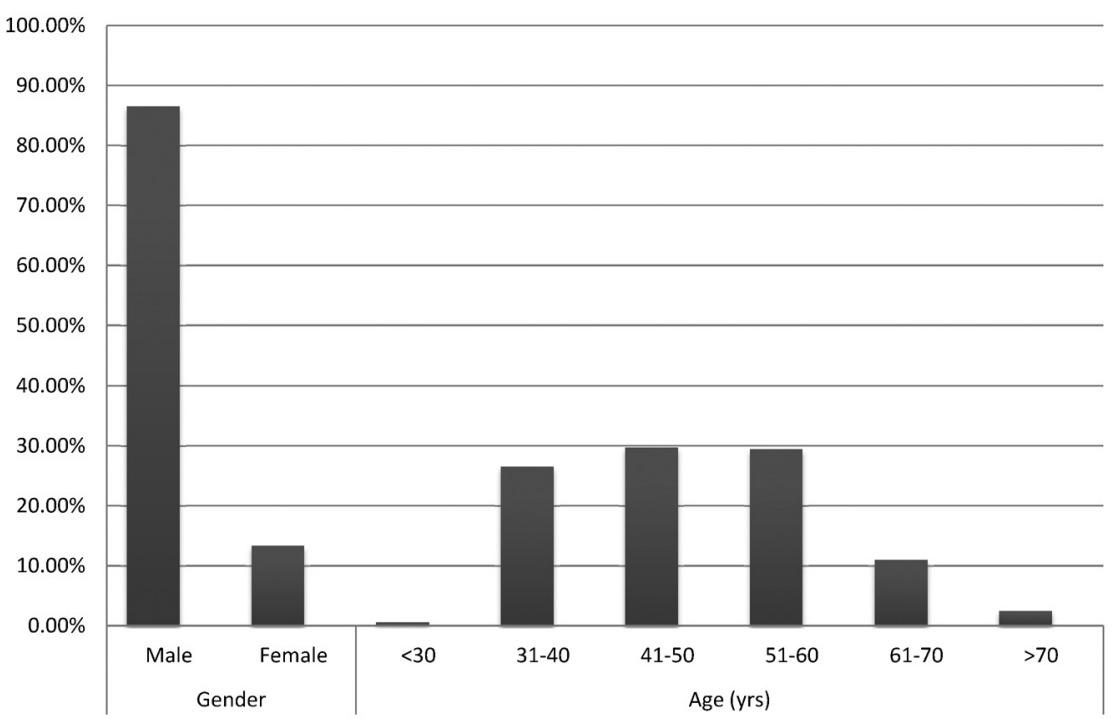

FIG 2. Demographic information of radiologists enrolled in the survey who answered the question about sex $(n=806)$ and age $(n=808)$.

The full results of the survey can be viewed at the following Web address:

http://www.surveymonkey.com/sr.aspx?sm=4y1SduJ73pus EREHU34PyiMKMhry2RDb9LzA3P06UCM_3d.

The survey was sent by means of a Web link. Through repeated e-mailing ( 2 reminders), a response rate of $20.7 \%$ (904/4357) was reached.

The survey was conducted by an outside vendor (SurveyMonkey, http://www.surveymonkey.com) and administered by the ASNR. Data were sent to the ASNR SurveyMonkey Web site. The data were anonymized without individual respondent identification. Confidentiality was ensured to respondents. Open-question answers were grouped for trends in responses by the 2 reviewers in concert, for example, lawsuits were still pending judgment, people were named in suits for no apparent reason, the medicolegal system must be reconstructed, and so forth. These open-ended comments were analyzed by 2 radiologists independently, and, if disagreements arose in the categorization of the comments, they met to achieve consensus.

\section{RESULTS}

Nine hundred four of 4357 ASNR members $(20.7 \%)$ answered at least 1 survey question, but as many as $117(2.7 \%)$ skipped various mandatory questions. Of these, 455 of $904(50.3 \%)$ said that they had never been sued during their career life and 449 of 904 (49.7\%) had been sued. One hundred eighty (44.9\%) of the 401 radiologists who answered the question said they had been sued once, 114 (28.4\%) had been sued twice, 60 (15.0\%) had been sued 3 times, and 47 (11.7\%) had been sued more than 3 times. If one uses 4 suits for the value of "more than 3 suits," these 401 respondents represent at least 776 claims in total (Fig 1). More than half of the 401 sued respondents had been sued 2 or more times.

Of these 904 respondents, 806-808 answered demographic questions. Of those providing sex data, $86.6 \%$ (698/ $806)$ were men and $13.4 \%(108 / 806)$ were women. Of the 808 who responded to the question about their age, most were between 41-60 years old (479/806; 59.4\%). Use of the midpoint of the age ranges for the categories yielded a mean age of 48.1 years, a median age of 50 years, and a mode of 45 years (Fig 2). Whereas just $13.7 \%(30 / 219)$ of respondents less than 40 years old had been sued, the percentage of those aged $41-50$ years who had been sued was $46.1 \%(111 / 241)$, and, for age group 51-60 years, it rose to $72.9 \%$ (172/ 236). Above this age, the percentage remained relatively steady at $72.5 \%(79 /$

109) (Fig 3). Thirty-eight and nine-tenths percent (42/108) of female neuroradiologists had been sued compared with 50.1\% (348/695) of male neuroradiologists; $35.7 \%$ (15/42) of women had been sued more than once compared with $57.4 \%$ (198/345) of men.

Among all radiologists answering survey questions, most practiced predominantly in diagnostic neuroradiology (657/771; $85.2 \%)$, with a small portion representing interventional neuroradiology (61/771; 7.9\%) and "in training" (44/771; 5.7\%); 49.7\% (325/657) of diagnostic and $57.4 \%$ (35/61) of interventional neuroradiologists had been sued.

The outcome for each lawsuit was available for 481 claims. Many lawsuits were noted to be still pending an outcome or no information was provided. Most of the lawsuits were dropped (270/481 cases; $56.1 \%$ ). Many suits were settled with a payout to the plaintiff (145/481 cases, $30.1 \%)$. Although a minority of cases 
went to a trial, the verdict was mostly in favor of the defendant (46/55 cases with a verdict; $83.6 \%$ ). Thus, between being dropped (270/481), settled without a payment (11/481), and a defense verdict in favor of the physician (46/481), a favorable outcome for physicians was noted in 68.0\% (327/481) (Table 1).

For diagnostic neuroradiologists, the rates of dropped, settled with a payment, settled without a payment, defense verdict, and plaintiff verdict were $57.4 \%$ (221/385), 29.4\% (113/385), 2.1\% (8/ $385), 1.3 \%$ (5/385), and 9.9\% (38/385), respectively. For interventionalists, these same rates were $49.0 \%$ (25/51), 37.3\% (19/51), $0 \%$, $5.9 \%(3 / 51)$, and $7.8 \%(4 / 51)$.

In terms of dollars paid to the plaintiff in settled or litigated cases, the most frequent amount paid for all the suits was less than $\$ 50,000$. The percentage of suits that had a mean payout of less than $\$ 50,000$ increased with increasing age [from $26 \%(6 / 23)$ of suits in the 41-50-year-old group to $75 \%$ (3/4) in those older than 70 years]. Regarding the most expensive payment for each lawsuit, the most frequently cited value was between $\$ 50,000$ and $\$ 150,000$ paid to the plaintiff (Fig 4). However, the most common average value of the suits cited was higher for interventional neuroradiologists ( $\$ 600,000$ to $\$ 1.2$ million) than diagnostic neuroradiologists (less than $\$ 50,000$ ).

Among causes of the alleged negligence, nondetection of a lesion was the most common $(31.0 \%=165 / 532)$, followed by complication of a procedure $[17.3 \%(92 / 532)$ overall but $60 \%$ (24/40) for interventional neuroradiologists] and misinterpretation of a finding $(16.0 \%, 85 / 532) ; 19.9 \%$ (106/532) of the respondents provided a comment regarding other reasons for being sued

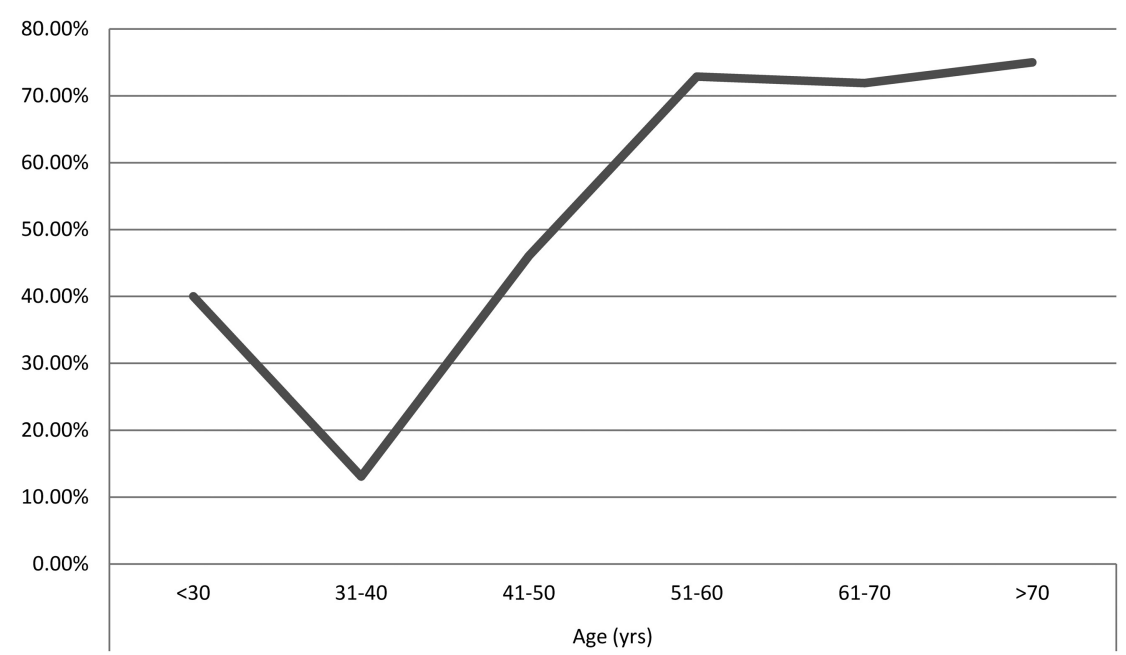

FIG 3. Percentage of the radiologists who answered, who were named in a malpractice lawsuit by age ( $<30$ years, $n=5$; 31-40 years, $n=214 ; 41-50$ years, $n=241 ; 61-70$ years, $n=89 ;>70$ years, $n=20)$. that were not mentioned as a survey choice. Of the comments provided, most said they were sued merely because they had their names on the radiology report (30 cases), there was a delay in treatment and/or diagnosis (20 cases), or there was a complication after a procedure (18 cases) (Table 2 ).

Table 3 depicts the respondents' fears and the main concerns about being sued. It shows that most neuroradiologists have mild $(199 / 784,25.4 \%)$ to moderately high $(235 / 784,30.0 \%)$ fear of being sued. Interestingly, with increasing age, the fear of being sued becomes progressively less, with $29.4 \%$ (5/17) of those older than 70 years, $22.5 \%(18 / 80)$ ages $61-70$ years, $14.9 \%(34 / 228)$ ages $51-60,10.5 \%(24 / 231)$ ages $41-50$, and $2.8 \%$ (6/210) of physicians younger than 40 years old never or rarely thinking about being sued. Women and men had similar ratings of their fears of being sued. The percentage of individuals expressing moderate to extreme fear of being sued was higher in those in training $(60.4 \%$, $26 / 43$ ) and doing neurointerventional procedures $(62.5 \%, 35 / 56)$ than for diagnostic neuroradiologists (48.0\%, 302/629).

Physicians were mainly concerned about the risk to their personal assets if they are sued (164/813,20.2\%). This was true for all age groups and either sex, except for the 41-50-year-old group, who were more concerned about losing their confidence leading to practicing defensive medicine. Women were also more concerned $(25 \%, 22 / 88)$ than were men $(15.4 \%, 91 / 592)$ about the impact of the malpractice on the injured plaintiff.

Respondents $(81.1 \%, 647 / 798)$ opined that the US judicial system is somewhat to heavily weighted in favor of the plaintiff (Table 4). As the age of the respondent increased, the degree to which they thought that the system favored the plaintiff decreased; $83 \%$ (87/ $105)$ of women and $80.7 \%(551 / 683)$ of men thought that the judicial system favored the plaintiff. A higher percentage of diagnostic $(81.3 \%, 522 / 642)$ than neurointerventionalists $(73.3 \%, 44 / 60)$ think the judicial system is biased against them.

\section{DISCUSSION}

Despite the large number of studies published about malpractice in the area of radiology, the rate at which neuroradiologists have been sued in the United States has not been specifically addressed. According to a recent study that provided the rate of radiologists sued with regard to organ system, ${ }^{4}$ neuroradiology's related organs ranked third (spinal, mus-

Table 1: Outcome for each lawsuit ( $n=481$ cases)

\begin{tabular}{lcccc}
\multicolumn{1}{c}{ Lawsuit Outcome } & Suit $\mathbf{n}(\%)$ & Suit $\mathbf{2} \boldsymbol{n}(\%)$ & Suit $\mathbf{3} \boldsymbol{n}(\%)$ & Total Count $\boldsymbol{n}(\%)$ \\
\hline It was dropped & $174(61.1)$ & $61(47.3)$ & $35(13.0)$ & $270(56.1)$ \\
The case was settled with a payout to the plaintiff & $74(26.0)$ & $50(38.8)$ & $21(14.5)$ & $145(30.1)$ \\
The case was settled without a payout to the plaintiff & $4(1.4)$ & $3(2.3)$ & $4(36.4)$ & $11(2.3)$ \\
The case went to trial with a plaintiff verdict & $4(1.4)$ & $4(3.1)$ & $1(11.1)$ & $9(1.9)$ \\
The case went to trial with a defendant verdict & $29(10.2)$ & $11(8.5)$ & $6(13.3)$ & 67 \\
Totals & 285 & 129 & & $48.6)$ \\
\hline
\end{tabular}




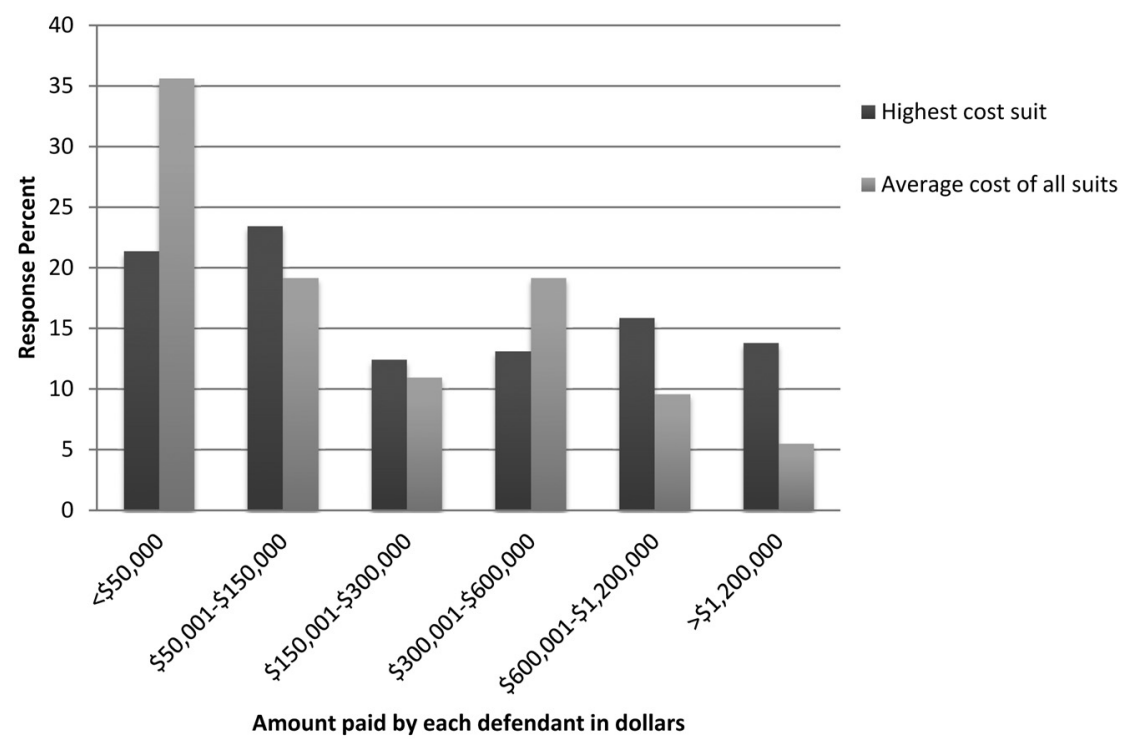

FIG 4. Highest cost and average amount paid (in dollars) by each defendant in the cases settled with a payout to the plaintiff, in percentage $(n=149)$.

Table 2: Nature of alleged negligence (number of total claims $=$ 532)

\begin{tabular}{lc}
\hline \multicolumn{1}{c}{ Nature of Alleged Negligence } & $\boldsymbol{n}(\%)$ \\
\hline Non-detection of a lesion & $165(31.0)$ \\
Misinterpretation of a finding (saw abnormality & $85(16.0)$ \\
but called it the wrong thing) & \\
Lack of communication of a finding & $54(10.2)$ \\
Technical error with machinery & $6(1.1)$ \\
Complication during performance of a procedure & $92(17.3)$ \\
Issue unrelated to a patient's study (fall, trip, & $16(3.0)$ \\
HIPAA violation) & $8(1.5)$ \\
Informed consent issue & $106(19.9)$ \\
Other & \\
\hline
\end{tabular}

culoskeletal) and sixth (brain) in position within the 15 organs cited.

To assess the rate of malpractice lawsuits in neuroradiology, we designed the present study through the use of the ASNR members as the study population. We hypothesized that a minority of ASNR members would be named in malpractice suits. Surprisingly, a large number of the respondents answered that they had been sued, with almost half saying that they had been named in at least 1 claim in their career (49.7\%). Of those who had been sued, most $(221 / 401=55.1 \%)$ answered that they had been sued twice or more.

A similar survey about malpractice stress syndrome in radiologists, performed in Italy, showed that the frequency of radiologists and radiotherapists who were named in a malpractice suit was one-third, which is less than our findings. ${ }^{8}$ That can be explained by the cultural difference between the incidence of lawsuits in both countries, which is higher in the United States than in Italy. Because we did not perform our study on a randomized population, that information may show a bias of who answered the poll and could also explain the high prevalence of ASNR members sued at least once in their professional career.

Concerning the rates of age and sex, our data agreed with a previous study that included demographic characteristics of malpractice claims against radiologists in the United States. ${ }^{6}$ Both studies found that the probability of being sued increased with years in practice, and men were sued more often than were women. Interventionalists had a higher rate of suits than did diagnostic neuroradiologists. This statement is in accord with previous study findings that found that procedural complications are one of the main causes of medical malpractice suits against radiologists in the United States. ${ }^{4}$

The study conducted in Italy showed that the relationship between age and the probability of being sued is contradictory because most of their respondents thought that older radiologists were more proficient than younger ones, though the youthful may be more up to date with advanced technology. ${ }^{8}$ By contrast, their respondents believed that newer radiologists are inclined to make more mistakes than are their more experienced coworkers. ${ }^{8}$ Meanwhile, it was theorized in the same study that advanced age and deteriorating cognitive skills might affect the capacity to identify radiologic findings. ${ }^{8}$ Certainly as years in practice extend, the prospect of being sued at least once increases with increasing age as more cases are read.

Comparing our data with a recent study that determined the most frequent causes of suits in US radiologists, ${ }^{4}$ there were similarities in the sources of suits between all of radiology and those related to the neuroradiology. We found that the main cause reported in our study was the nondetection of a finding, which is in agreement with what the previous authors described as "failure to diagnose" as the most common cause of malpractice suits in general radiology. We also found that our next most common causes of suits, complications during performance of a procedure and the lack of communication of a finding, were near the top of their results as well. ${ }^{4}$ It is important to highlight that the previously mentioned study reviewed cases mainly related to breast imaging because mammography suits lead to most claims in the United States (followed by malpractice suits related to fractures). ${ }^{4}$ Notwithstanding, our findings were compatible with the general radiology results.

In addition to the assessment regarding the frequency information about the malpractice lawsuits in neuroradiology, we sought to evaluate the opinions of neuroradiologists concerning malpractice litigation and the judicial system. It was assumed that the fear of being sued was unfounded. That hypothesis was discredited, and only $25.4 \%$ of the respondents had mild fear of being sued and $30.0 \%$ were occasionally concerned, whereas only $6.5 \%$ were always concerned with being sued in their career life.

It has been suggested that physicians who are most concerned with the probability of being sued are often the ones who had already been through malpractice litigation. The literature shows that some physicians who responded to a lawsuit would have had a malpractice syndrome, which includes tension, anxiety, low selfesteem, depression, frustration, and insomnia, among other 
Table 3: Extent of fear and concerns about being sued

\begin{tabular}{lclc}
\hline \multicolumn{1}{c}{ Fear of Being Sued } & $\boldsymbol{n}(\%)$ & \multicolumn{1}{c}{ Main Concern About Being Sued } & $\boldsymbol{n}(\%)$ \\
\hline Extremely low: Never think about it & $29(3.7)$ & Reputation among peers & $57(7.0)$ \\
Very low: Rarely crosses my mind & $60(7.6)$ & The cost of malpractice insurance & $38(4.7)$ \\
Relatively low: Not very concerned & $113(14.4)$ & Personal assets at risk & $165(20.2)$ \\
Mild & $199(25.3)$ & The impact on the patient who is “injured" & $117(14.4)$ \\
Moderately high: occasionally concerned & $235(29.9)$ & Lose his/her own confidence and practice defensive medicine & $156(19.1)$ \\
Very high: frequently concerned & $99(12.6)$ & The impact on the overall health care system & $43(5.3)$ \\
Extremely high: always concerned & $51(6.5)$ & Being named in the national practitioners data bank & $87(10.7)$ \\
& & Unfavorable publicity in the media & $12(1.5)$ \\
& & Ego & $20(2.5)$ \\
Totals & & Other & $120(14.7)$ \\
\hline
\end{tabular}

Table 4: Fairness of malpractice legal process in the United States

\begin{tabular}{|c|c|c|c|}
\hline $\begin{array}{c}\text { Assessment of the Malpractice Legal Process in } \\
\text { the United States }(n=798)\end{array}$ & $n(\%)$ & $\begin{array}{l}\text { General Comments About Malpractice Litigation } \\
\text { in United States }(n=94)\end{array}$ & $n(\%)$ \\
\hline Heavily weighted to plaintiff & $275(34.5)$ & It is unfair & $27(23.7)$ \\
\hline Somewhat weighted to the plaintiff & $372(46.6)$ & Negative about lawyers in general/uniformly & $23(20)$ \\
\hline Fair & $93(11.7)$ & We all make mistakes & $15(13)$ \\
\hline Somewhat weighted to the defendant & $46(5.8)$ & We should punish bad experts & $8(7)$ \\
\hline \multirow[t]{3}{*}{ Heavily weighted to the defendant } & $12(1.5)$ & We need another system/arbitration panels & 12 (11) \\
\hline & & The system is good & $1(1)$ \\
\hline & & Tort reform is needed & $8(7)$ \\
\hline
\end{tabular}

Note: $-n$ indicates total of respondents for each question.

symptoms. ${ }^{8}$ Thus, it would lead the physician to be more concerned about being named in another lawsuit in the future and to adopt a defensive practice. Unfortunately, we were not able to make that correlation with the use of our data base.

Our study demonstrated that most of the lawsuits in the area of neuroradiology were dropped or settled with payment to the plaintiff, but that payment was most commonly less than $\$ 50,000$. The questions were not specific to know whether this represented the individual radiologist's "share" of the payment or the payment for the all members of the case. When going to trial, the verdict was in favor of the defendant in 46 of 55 (83.6\%) cases (Table 1). These data are in agreement with the $\mathrm{PIAA}^{3}$ in regard to the malpractice lawsuits of physicians in the United States. Our survey showed that most frequently, the largest compensation paid to plaintiffs in these suits was between $\$ 50,000$ and $\$ 150,000$. According to PIAA, this is below the associated mean legal costs per suit, when considering cases that are either settled or litigated, which lies between $\$ 200,000$ and $\$ 375,000$.

One apparent contradiction identified in our survey is the high rate of favorable outcomes (dropped suits, settlements without payment, court judgments in favor of defendants) and low payouts (less than $\$ 50,000$ selected most commonly) yet the perception by neuroradiologists that the medicolegal system is heavily weighted toward the plaintiffs. This may be because of the perceived ease with which a plaintiff may bring a suit against a physician.

The other paradox that we noted was the relatively low rate of suits cited with a payout more than $\$ 150,000$ for diagnostic neuroradiologists yet the fear among neuroradiologists that their personal assets may be at risk. Because most physicians carry malpractice insurance coverage for $\$ 1,000,000$ per case and very few cases exceed that value, the risk to one's personal assets would seem highly improbable.

These paradoxes may be explained by the Prospect Theory, proposed by Kahneman and Tversky, awarded the Nobel Prize in Economics in 2002. ${ }^{9}$ They showed, through experimental behavior, that the decisions made by human beings follow some patterns that are not necessarily based on probabilities only. Thus, people will alter their behavior on the value of the gains or losses rather than on the probability of the occurrence. Therefore, even though the probability of being sued is low and even though the likelihood of one's personal assets being encumbered is low, because of the negative impact and high "value" of these potential outcomes, physicians alter their behavior to avoid that potentiality. On the basis of the Prospect Theory, people "overvalue" the risks. This may explain why healthy people still buy health insurance and why outstanding physicians, even if it was optional, would still buy malpractice insurance. It also explains why physicians will change practice patterns even though the risk of malpractice suits may be quite small. ${ }^{9,10}$

\section{Limitations}

The major limitation of our study is the potential for selection bias, with only 904 of 4357 neuroradiologists answering survey questions. We believe this was caused in part by a high rate of surveys submitted for participation by the ASNR this year on top of the customer service and patient satisfaction and job satisfaction surveys that have become standard fare in medicine. Physicians may have survey fatigue. Some questions were answered by far fewer respondents. This limits the reliability of the calculated response rates to each specific question. For example, the overall rate of malpractice suits might be overrepresented if ASNR members who had been sued were more likely to spend the time filling out the survey to share their experience, or the suit rate could be underestimated if physicians were embarrassed about having been named in a suit, justly or unjustly, and either did not answer truthfully or did not respond to the survey at all because of unhappy associations with the topic. Selection bias is a limitation of 
all survey-based investigations, and the similarity between our results and previously published rates suggests that this source of bias did not play a major role in our results.

The study also did not control for the respondents' ages across sex and practice patterns (diagnostic versus interventional), nor did it assess whether the respondent was in the private, academic, or government sector. In addition, the survey did not inquire as to the home country of the respondent. The ASNR now has a significant number of non-American members among which the incidence of malpractice suits is lower than in the United States. The ASNR also has a small percentage of nonclinical research scientists, unlikely to be named in a suit, who may have diluted the malpractice sample.

We also had a plethora of open-ended comments for cases in which the respondents did not select the proffered choices in the survey. These responses could not be counted by the rates shown in the tables and graphics, but they were analyzed by the authors and added to the results and discussion, on the basis of our interpretation of the comments. The fact that so many people added comments to many of the questions may be related to 1) the emotionally charged nature of the topic, 2) many respondents' answers did not fit into the choices provided, and 3) simple options in a multiple choice format cannot tell the full story of what physicians experienced in their medicolegal environment.

We were not able to detail the major economic concerns of respondents with respect to litigation expenses. The impact of days away from work, practice expenses litigating cases, malpractice insurance limits, and increased premiums for malpractice insurance were issues not addressed in this survey.

\section{CONCLUSIONS}

Almost half of the ASNR respondents have been sued at least once, and, of those named in a suit, more than half have been named in more than 1 suit. These suits tend to be about nondetection of lesions, complications of procedures, misinterpretation of a finding, or perceived random naming of a physician whose name was in the medical record. Although the outcomes overall reported are heavily weighted toward physicians by virtue of many dropped suits, small payouts, defense verdicts, or favorable settlements, neuroradiologists have a high level of anxiety about being sued that affects many physicians on a daily basis. Many fear that their personal assets may be at risk despite the favorable outcomes listed above and the extremely low risk of personal exposure. This may be because, although the probability of such an event is low, the value placed on loss of assets is very high, as explained by the Prospect Theory. Therefore, behaviors to reduce the likelihood of that improbable event may still be used. Overall, the neuroradiologists responding believe that the medicolegal system is strongly to somewhat heavily biased in favor of plaintiffs.

\section{ACKNOWLEDGMENTS}

We would like to express our appreciation to Angelo Artemakis for his help in constructing our survey questionnaire and for collating the results of this research study.

Disclosures: Kelly Yousem-OTHER RELATIONSHIPS: While I do not believe this influenced the report, it should be noted I am a medical malpractice attorney. David Yousem—UNRELATED: Expert Testimony: Medicolegal consultations; Payment for Lectures (including service on speakers' bureaus): ACR Education Center, Comments: Compensation received both directly and by institution; Royalties: Elsevier, for 3 books; Payment for Development of Educational Presentations: ACR Education Center, Comments: Compensation received both directly and by institution.

\section{REFERENCES}

1. Jena AB, Chandra A, Lakdawalla D, et al. Outcomes of medical malpractice litigation against US physicians. Arch Intern Med 2012;172:892-94

2. Jena AB, Seabury S, Lakdawalla D, et al. Malpractice risk according to physician specialty. $N$ Engl J Med 2011;365:629-36

3. Claim Trend Analysis: A Comprehensive Analysis of Medical Malpractice Data Reported to the PIAA Data Sharing Project. Physician Insurers Association of America, Rockville, Maryland. 2004

4. Whang JS, Baker SR, Patel R, et al. The causes of medical malpractice suits against radiologists in the United States. Radiology 2013;266:548-44

5. Thomson NB 3rd, Patel M. Radiology liability update: review of claims, trends, high-risk conditions and practices, and tort reform alternatives. J Am Coll Radiol 2012;9:729-33

6. Baker SR, Whang JS, Luk L, et al. The demography of medical malpractice suits against radiologists. Radiology 2013;266:539-47

7. Studdert DM, Mello MM, Gawande AA, et al. Claims, errors, and compensation payments in medical malpractice litigation. $N$ Engl J Med 2006;354:2024-33

8. Fileni A, Magnavita N, Mammi F, et al. Malpractice stress syndrome in radiologists and radiotherapists: perceived causes and consequences. Radiol Med (Torino) 2007;112:1069-84

9. Kahneman D, Tversky A. Prospect theory: an analysis of decision under risk. Econometrica 1979;47:263

10. Lawthers AG, Laird NM, Lipsitz S, et al. Physicians' perceptions of the risk of being sued. J Health Polit Policy Law 1992;17:463-82 